\title{
Operative versus nonoperative treatment in children with painful rigid flatfoot and talocalcaneal coalition
}

Giovanni Luigi Di Gennaro', Stefano Stallone', Eleonora Olivotto², Paola Zarantonello', Marina Magnani', Tullia Tavernini ${ }^{1}$, Stefano Stilli ${ }^{1}$ and Giovanni Trisolino ${ }^{1 *}$

\begin{abstract}
Background: The management of painful rigid flatfoot (RFF) with talocalcaneal coalition (TCC) is controversial. We aimed to compare operative and nonoperative treatment in children with RFF and TCC.

Methods: We retrospectively reviewed medical records and radiographs of children with RFF and TTC treated between 2005 and 2015. The nonoperative treatment consisted of manipulation under anesthesia, cast immobilization and shoe insert after cast removal. The operative treatment consisted of combined TCC resection, graft interposition and subtalar arthroereisis.

Results: Thirty-four children ( $47 \mathrm{ft}$ ) in the nonoperative group and twenty-one children ( $34 \mathrm{ft})$ in the operative group were included. No differences were found between groups, concerning baseline characteristics. The mean age at treatment was 11.8 years (9-17): 11.6 (9-17) for the nonoperative group, $12.2(10-15)$ for the operative group. The mean follow-up averaged 6.6 (3-12) years and was significantly longer in the nonoperative group (7.8 versus 4.7 years; $p<0.0005$ ), since the operative procedure was increasingly practiced in the latest years.

There were no complications in either groups, but 6 patients $(7 \mathrm{ft})$ in the nonoperative group were unsatisfied and required surgery. At the latest follow-up, the AOFAS-AHS improved in both groups, although the operative group showed significantly better improvement. The operative group reported also significantly better FADI score, after adjustment for follow-up and baseline variables.
\end{abstract}

Conclusion: The operative treatment showed better results compared to the nonoperative treatment. Symptomatic RFF with TCC in children can be effectively treated in one step with resection, graft interposition and subtalar arthroereisis. Further prospective randomized studies are needed to confirm our findings and to identify the best operative strategy in this condition.

Keywords: Tarsal coalition, talocalcaneal, Flatfoot, Child, Surgical treatment, Manipulation under anesthesia, Allograft, Arthroereisis

\footnotetext{
* Correspondence: giovanni.trisolino@ior.it

'Pediatric Orthopedics and Traumatology, IRCCS Istituto Ortopedico Rizzoli, Bologna, Italy

Full list of author information is available at the end of the article
}

(c) The Author(s). 2020 Open Access This article is licensed under a Creative Commons Attribution 4.0 International License, which permits use, sharing, adaptation, distribution and reproduction in any medium or format, as long as you give appropriate credit to the original author(s) and the source, provide a link to the Creative Commons licence, and indicate if changes were made. The images or other third party material in this article are included in the article's Creative Commons licence, unless indicated otherwise in a credit line to the material. If material is not included in the article's Creative Commons licence and your intended use is not permitted by statutory regulation or exceeds the permitted use, you will need to obtain permission directly from the copyright holder. To view a copy of this licence, visit http://creativecommons.org/licenses/by/4.0/. The Creative Commons Public Domain Dedication waiver (http://creativecommons.org/publicdomain/zero/1.0/) applies to the data made available in this article, unless otherwise stated in a credit line to the data. 


\section{Background}

The congenital tarsal coalition is a partial or complete fusion between two or more midfoot or hindfoot bones, due to abnormal formation of bone, cartilage or fibrous tissue [1].

The incidence of tarsal coalition is about 1\%, although, being often asymptomatic, the true prevalence is around $13 \%$ [2-6], with a male predominance and bilaterality in $50 \%$ of cases [1]. The talocalcaneal coalition (TCC) and the calcaneo-navicular coalition (CNC) are the most frequent compared to other types $[7,8]$.

Many patients with TCC typically show a rigid flatfoot (RFF) with loss of the medial arch $[5,9]$. RFF must be distinguished from flexible flatfoot (FFF). FFF is a widespread idiopathic condition among children. In contrast with RFF, FFF is clinically characterised by the possibility of restoring a medial arch at physical examination when standing on tip toes or with the Jack's test (rise of the medial arch with great toe passive dorsiflexion) [10, 11]. Compared to FFF, RFF is most frequently symptomatic [12]. Pain is present in about $25 \%$ of cases; symptoms generally start in the second decade of life, when the coalition ossifies $[2,9]$. The management of symptomatic RFF with TCC is controversial [13]. Many authors agree that conservative treatment must be initially attempted, while surgery should be reserved when conservative treatment fails [1, 13-16].

Historically, subtalar or triple arthrodesis has been recommended for pain relief $[17,18]$. More recently, some authors reported good results following bar resection, possibly associated with interposition of various tissues $[8,19-24]$. This treatment aims to relieve pain and increase subtalar motion.

Moreover, some authors stressed the importance of the correction of the hindfoot alignment, during the management of painful RFF with TCC [19, 25-29].

The aim of this study was to compare nonoperative and operative treatment in children affected by TCC and RFF.

\section{Methods}

After institutional review board approval, a retrospective review of medical records and radiographs was conducted in patients admitted for painful RFF with TTC between 2005 and 2015 at a single tertiary referral center for pediatric orthopedics. The study involved 55 children ( 35 males, 20 females; 26 bilateral cases) accounting for overall $81 \mathrm{ft}$. All the patients were treated according to the surgeon's preference and experience thus the study was not randomized. Children with painful TCC and RFF (defined "Staheli Arch Index" $>1.28$ and rearfoot eversion $>10^{\circ}$ [30, 31]) were enrolled. Computed Tomography (CT) was performed to confirm the diagnosis. We divided our cohort in two groups: A) nonoperative, consisting of manipulation under anesthesia and cast application (34 children; $47 \mathrm{ft}$ ); B) operative, consisting in TCC resection, graft interposition and subtalar arthroereisis (21 children; $34 \mathrm{ft}$ ).

We excluded from the study: children treated for idiopathic or secondary flatfoot without tarsal coalition; tarsal coalitions other than TCC; children who underwent other operations; children with syndromic pathologies or neuromuscolar disorder; children with incomplete documentation or lost to follow-up.

An Italian validated version of the American Orthopaedic Foot and Ankle Society Ankle-Hindfoot Score (AOFAS-AHS) was completed at admission for each patient [32], .Lateral talar-first metatarsal angle and calcaneal pitch were calculated on radiographs. On CT we assessed the heel valgus, the coalition area, the subtalar joint space narrowing (JSN) and the presence of osteoarthritis (OA) of the subtalar joint [19, 33-35]. The tarsal coalition was classified according to the Rozansky's classification [19, 33, 34].

Nonoperative treatment consisted of manipulation in supination under anesthesia; then a short-leg cast in inversion was applied for 5 weeks [18]. After cast removal, patients received custom shoe inserts to reduce overpronation and support plantar arch.

The operative treatment consisted of combined TCC resection, allograft interposition and correction of the hindfoot alignment by subtalar athroereisis with a nonresorbable screw (SPHERUS talar screw, Gruppo Bioimpianti ${ }^{\circledR}$ - Milan - Italy).

\section{Surgical technique}

The patient was placed in supine position, with a pneumatic torniquet on the tight. A medial incision was performed, starting from the posterior apex of the medial malleolus, continuing for $5 \mathrm{~cm}$ over the sustentaculum tali, until the posterior border of the palpable navicular bone (Fig. 1a). The tendon sheath was incised longitudinally, to expose the tibialis posterior tendon, that was retracted dorsally, while flexor hallucis longus and flexor digitorum longus tendons were retracted plantarly (Fig. 1b). The deltoid ligament was dissected over the bone bridge, that was exposed, identifying the talonavicular joint anteriorly and the residual talocalcaneal joint posteriorly. The bridge was excised with an osteotome, obtaining separation and complete motion of the talocalcaneal joint (Fig. 1c). A calibrated spreader was used to obtain an adequate gap for insertion of the graft (Fig. 1d). A lateral incision was performed over the sinus tarsi, identifying the lateral facet of the talus and exposing the tarsal canal. A frozen fascia lata allograft was 


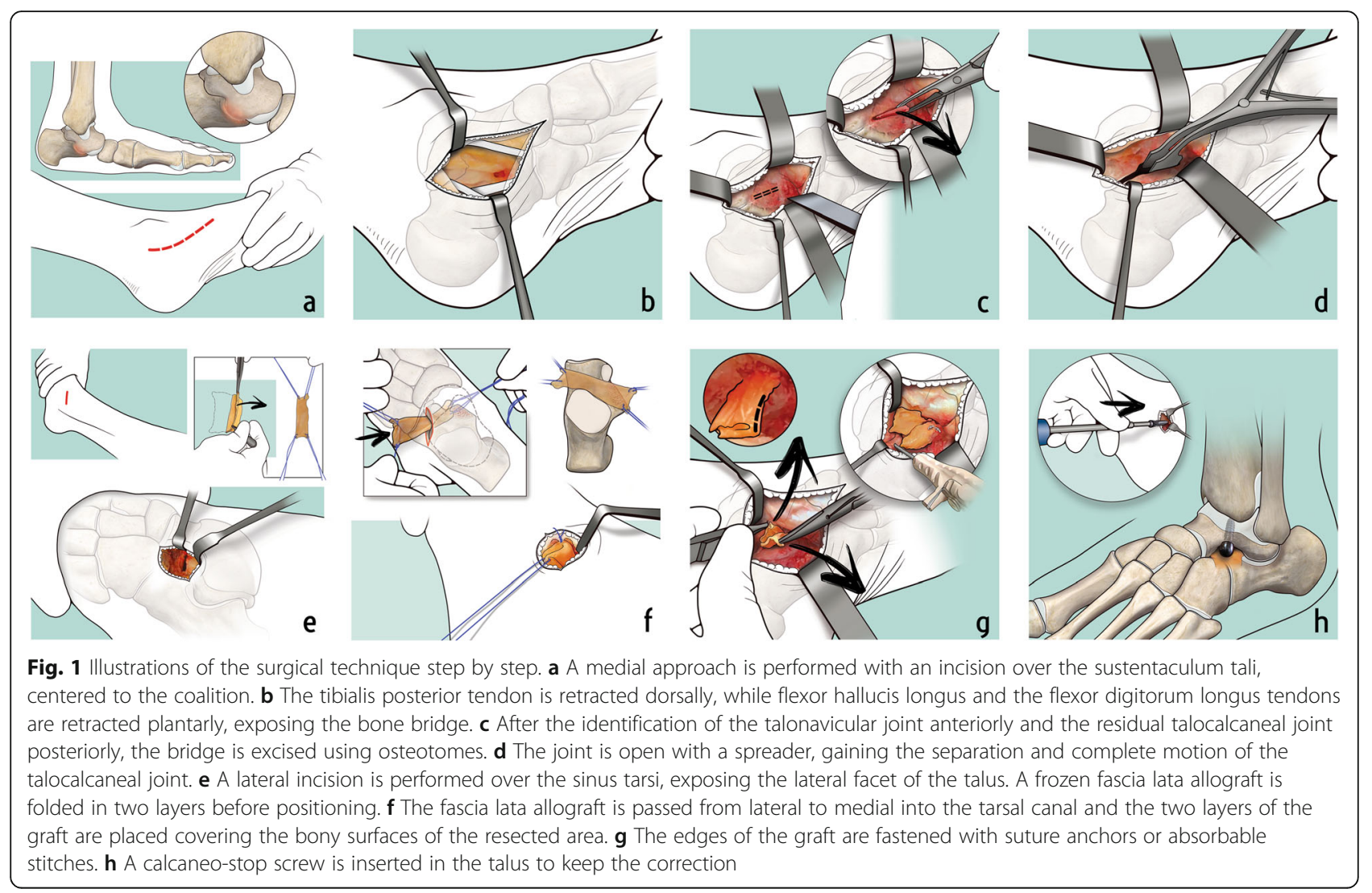

folded in two layers before positioning (Fig. 1e). The size of the allograft was prepared according to the size of the resected area. A blunt dissection was performed to slightly dilate the tarsal canal and facilitate the graft passage. The graft was passed into the tarsal canal and the two layers of the graft were carefully placed on the bony surfaces of talus and calcaneus at the level of the coalition, mimicking the articular surfaces of the talocalcaneal joint [36] (Fig. 1f). The edges of the graft were fastened to the surrounding bony or capsular structures, using suture anchors or absorbable stitches (Fig. 1g). Using the same lateral approach, a screw housing was prepared by a straight awl, and the body of the talus was penetrated obliquely upwards. Under fluoroscopic control, a talar screw was then inserted in the housing, until the spherical head of the screw, projecting into the sinus tarsi and resting against the floor of the latter, provided the desired degree of correction (Fig. 1h). The tension of the Achilles' tendon was checked, and a percutaneus tendon lenghtening, was further performed, whenever the ankle did not achieve at least $5^{\circ}$ of dorsiflexion with the knee flexed.

A plaster cast was applied for 4 weeks. After cast removal, walking with full weight bearing was allowed as soon as pain was tolerable.
The screw was removed after 2 years, if the foot increased by two or more shoe sizes.

\section{Follow-up}

Patient were followed for at least 3 years (at least 1 year after screw removal in the operative group). Data were collected and analyzed by two independent observers. The clinical and functional outcomes were assessed by the AOFAS-AHS and the Italian validated version of the Foot and Ankle Disability Index (FADI) [37]. Both questionnaires were completed during the latest follow-up visit. Postoperative radiographs were available only in 4 cases in the nonoperative group and in 13 cases in the operative group, thus the differences between preoperative and postoperative radiographic values were not evaluated.

\section{Statistical analysis}

Continuous data were expressed as means, whereas categorical and ordinal data were expressed as absolute values and percentages. Normality was tested using the chi-square test for categorical variables and the Kolmogorov-Smirnov test for continuous variables. Differences in baseline and outcome characteristics between groups were tested using Fisher's exact test for categorical variables and Student's t-test for paired and 
unpaired data (normal distribution) or Mann-Whitney U-test and Wilcoxon signed-rank test (skewed distribution) for continuous variables. Exploratory univariable analyses with general linear models were performed to identify potential associations among baseline variables and outcomes. Linear mixed effect models with patient as random effect were used, to avoid violation of the principle of independence in bilateral cases. Results were presented as crude and adjusted means with 95\% Confidence Intervals.

Propensity analysis was used for adjustment of potential selection biases in operative decision [38]. For each patient, we estimated propensity scores (PS) for receiving nonoperative or operative treatment, using a binary logistic model that included baseline variables. The balance of the PS was checked observing the overlap in the range of propensity scores across the two treatments and comparing the quintiles. T-test showed no statistically significant differences in covariate means between groups after matching. Examining treatment effects on the outcome across PS quintiles, no association was observed between the outcome and the probability of receiving either treatment, meaning that there is no evidence of unmeasured bias. PS were used to derive inverse probability of treatment weights (IPTW), with the inverse of the propensity score for the operative group and the inverse of 1 minus the propensity score for nonoperative group. Then, the IPTW were used to adjust the difference in AOFAS-AHS and FADI between groups. Statistical significance was set at $p<.05$. All analyses were performed with SPSS v. 22.0 (SPSS, Chicago, IL, USA).

\section{Results}

No differences were found between groups, concerning age at treatment, gender, bilaterality, baseline AOFASAHS, radiographic features (see Table 1).

The mean age at treatment was 11.8 years (9-17): 11.6 (9-17) for the nonoperative group and $12.2(10-15)$ for the operative group There were no correlations between AOFA-AHS at baseline and sex, age, bilaterality, radiografic features. In all cases, the area of the coalition involved less than $50 \%$ of the subtalar joint and no radiographic OA was observed. The mean hospitalization time was 6 days (range 3-10) in the operative group and 4 days (range 1-9) in the nonoperative group. With the numbers available, the difference was not statistically significant ( $p$-value $=0.884$ ).

The mean follow-up averaged $6.6(3-12)$ years and was significantly longer in the nonoperative group (7.8 versus 4.7 years; $p<0.0005)$, since the operative procedure was increasingly practiced in the latest years.

At the latest follow-up, the AOFAS-AHS significantly increased in both groups, although the operative group showed more pronunced improvements (see Table 2). Also the FADI score was better in the operative group, after adjustment for follow-up duration and IPTW (estimated mean 81 points in the nonoperative group versus 93 points in the operative group. $p$-value $<.0005$. See Table 3 ). Return to regular sport activity was possible after an average period

Table 1 Baseline demographic, clinical and radiographic data

\begin{tabular}{|c|c|c|c|}
\hline Baseline variable & Group A (nonoperative) & Group B (operative) & $p$-value \\
\hline $\mathrm{N}^{\circ}$ of children (feet) & $34(47)$ & $21(34)$ & .07 \\
\hline Male/female ratio & $23 / 11$ & $12 / 9$ & .35 \\
\hline Age (years) [mean \pm SD (range)] & $11.6 \pm 2.1(9-17)$ & $12.2 \pm 1.2(10-15)$ & .07 \\
\hline AOFAS-AHS pain [mean \pm SD (range)] & $28 \pm 4(20-40)$ & $28 \pm 5(20-30)$ & .71 \\
\hline AOFAS-AHS function [mean \pm SD (range)] & $42 \pm 3(35-47)$ & $42 \pm 4(27-47)$ & .76 \\
\hline AOFAS-AHS alignment [mean \pm SD (range)] & $1 \pm 2(0-10)$ & $1 \pm 2(0-5)$ & .29 \\
\hline AOFAS-AHS tot [mean \pm SD (range)] & $70 \pm 7(55-87)$ & $70 \pm 7(47-82)$ & .47 \\
\hline Radiographic data & Group A (nonoperative) & Group B (operative) & $p$-value \\
\hline Calcaneal Pitch $\left(^{\circ}\right)$ [mean \pm SD (range) $]$ & $13.7 \pm 3.9(9-20)$ & $14.7 \pm 3.1(11-21)$ & .48 \\
\hline Meary's angle $\left(^{\circ}\right)[$ mean \pm SD (range)] & $12.6 \pm 4.3(8-20)$ & $13.3 \pm 4.7(9-21)$ & .82 \\
\hline Heel valgus $\left(^{\circ}\right)[$ mean $\pm S D($ range $)]$ & $23.7 \pm 8.8(6.6-46.8)$ & $26.4 \pm 7.7(12.8-38.5)$ & .37 \\
\hline$J S N(m m)[$ mean \pm SD (range)] & $2.8 \pm 1.0(0.6-4.8)$ & $2.7 \pm 0.9(1.7-4.8)$ & .28 \\
\hline \multirow[t]{5}{*}{ Rozansky classification } & I: 13 & l: 18 & .19 \\
\hline & l: 9 & I: 4 & \\
\hline & III: 12 & III: 7 & \\
\hline & IV: 8 & IV: 4 & \\
\hline & V: 5 & $\mathrm{~V}: 1$ & \\
\hline
\end{tabular}


Table 2 Comparison between baseline and latest follow-up AOFAS-AHS in the nonoperative and operative groups. The results are expressed as estimated means

\begin{tabular}{|c|c|c|c|c|c|c|c|}
\hline \multirow[t]{2}{*}{ Clinical outcome } & \multicolumn{3}{|c|}{ Group A (nonoperative) } & \multicolumn{3}{|c|}{ Group B (operative) } & \multirow[t]{2}{*}{$p$-value } \\
\hline & baseline & follow-up & MD & baseline & follow-up & MD & \\
\hline AOFAS-AHS pain & $28(26-29)$ & $30^{*}(28-32)$ & $2(-1-5)$ & $28(26-30)$ & $37^{* *}(34-39)$ & $9(6-12)$ & .002 \\
\hline AOFAS-AHS function & $42(41-43)$ & $43^{*}(41-45)$ & $1(-1-3)$ & $42(40-43)$ & $47^{* *}(45-49)$ & $6(4-8)$ & .04 \\
\hline AOFAS-AHS alignment & $1(0-2)$ & $5^{* *}(4-6)$ & $4(3-6)$ & $1(0-2)$ & $10^{* *}(9-11)$ & $9(7-10)$ & .001 \\
\hline AOFAS-AHS total & $70(68-73)$ & $78^{* *}(74-82)$ & $8(3-12)$ & $71(68-73)$ & $94^{* *}(89-98)$ & $24(19-29)$ & $<.0005$ \\
\hline
\end{tabular}

The estimated means were adjusted by inverse probability of treatment weights (IPTW) and follow-up duration (covariates were calculated at 6.5 years of followup), using the patient as random effect to avoid violation of the principle of independence in bilateral cases. $95 \%$ confidence interval of the estimated mean is reported in brackets

$\mathrm{MD}=$ Mean Difference between baseline and latest follow-up AOFAS-AHS

The asterisks refer to the statistical difference between baseline and follow-up values within the same group. * difference is significant at $p<.05$. **: difference is significant at $p<.0005$

The $P$-value in the last column is referred to the statistical difference between the MD of the two groups

of 10 months (range $5-31$ ) in the operative group and after 7 months (range 1-12) in the nonoperative group. ( $p$-value $=0.096)$. With the numbers available, age, gender, AOFAS-AHS at baseline and radiographic parameters did not affect the final outcome.

In the nonoperative group, no complications (such as iatrogenic fractures, compartment syndrome, pressure sores, thermal injuries, dermatitis, deep vein thrombosis, reflex sympathetic dystrophy) were reported, but 6 patients $(7 \mathrm{ft})$ were unsatisfied with the nonoperative treatment and required surgery 2 to 4 years after treatment. In the operative group, we did not report any complication related to the operation. In 4 patients $(5 \mathrm{ft})$ a percutaneous achille's tendon lenghtening was performed during the operation, in order to achieve $5^{\circ}$ of ankle dorsiflexion.

An example is showed in Fig. 2.

\section{Discussion}

To the best of our knowledge, we described the largest case-control study comparing operative and nonoperative treatment of TCC with RFF (see Table 4). We found that operative treatment, consisting in a one-step procedure combining TCC resection, graft interposition and subtalar arthroereisis, may produce better clinical and functional results compared to nonoperative treatment.
Currently, poor evidence supports the management of painful RFF with TCC in children. Recommended treatment includes manipulation, continuous or intermittent casting and orthosis, while surgery is generally reserved to those cases in which nonoperative treatment fails [1, 13-15, 41].

Concerning the nonoperative treatment, it can relieve pain and improve function in $25-68 \%$ of cases [18, 40, 43, 61-63]. Most authors suggested that surgery should be performed on patients whose symptoms were not relieved by conservative treatment. However, previous reports about nonoperative treatment were often weakened by limited statistical analysis or lack of essential outcome measures. We found that nonoperative management produced satisfactory outcomes (total AOFAS-AHS > 80) in 55\% of cases and $7 \mathrm{ft}(15 \%)$ required surgery after nonoperative treatment. These results are consistent with previous studies investigating the role of nonoperative treatment of RFF with TCC [43, 61]. Moreover, in our experience, the manipulation under anesthesia and casting was much more expensive than other nonoperative strategies (for instance, analgesia, physiotherapy and orthotics) since, it contempated an average hospitalization of 4 days and a mean surgical room occupation of $30 \mathrm{~min}$. Therefore we believe that this treatment should be reserved only to those cases in which other nonoperative treatments failed, that need

Table 3 Post-operative clinical and functional outcome measured and FADI

\begin{tabular}{|c|c|c|c|c|c|}
\hline \multirow{2}{*}{$\begin{array}{l}\text { Clinical } \\
\text { outcome }\end{array}$} & \multicolumn{2}{|c|}{ Group A (nonoperative) } & \multicolumn{2}{|c|}{ Group B (operative) } & \multirow[t]{2}{*}{$p$-value } \\
\hline & Crude mean & Estimated mean & Crude mean & Estimated mean & \\
\hline FADI tot & $83(57-100)$ & $81(78-84)$ & $92(64-100)$ & $93(87-98)$ & $<.0005$ \\
\hline FADI pain & $87(50-100)$ & $85(82-100)$ & $94(69-100)$ & $97(92-100)$ & $<.0005$ \\
\hline FADI function & $85(59-100)$ & $84(81-87)$ & $93(64-100)$ & 94 (90-98) & .03 \\
\hline FADI sport & $74(47-100)$ & $72(68-77)$ & $87(63-100)$ & $86(80-93)$ & $<.0005$ \\
\hline
\end{tabular}

Group A: non-operative group. Group B (operative group). The results are expressed as crude and estimated means. The crude means are reported as mean and range. The estimated means were adjusted by inverse probability of treatment weights (IPTW) and follow-up duration (covariates were calculated at 6.5 years of follow-up), using the patient as random effect to avoid violation of the principle of independence in bilateral cases. $95 \%$ confidence interval of the estimated mean is reported in brackets. The $P$-value in the last column is referred to the statistical difference between the estimated means of the two groups 

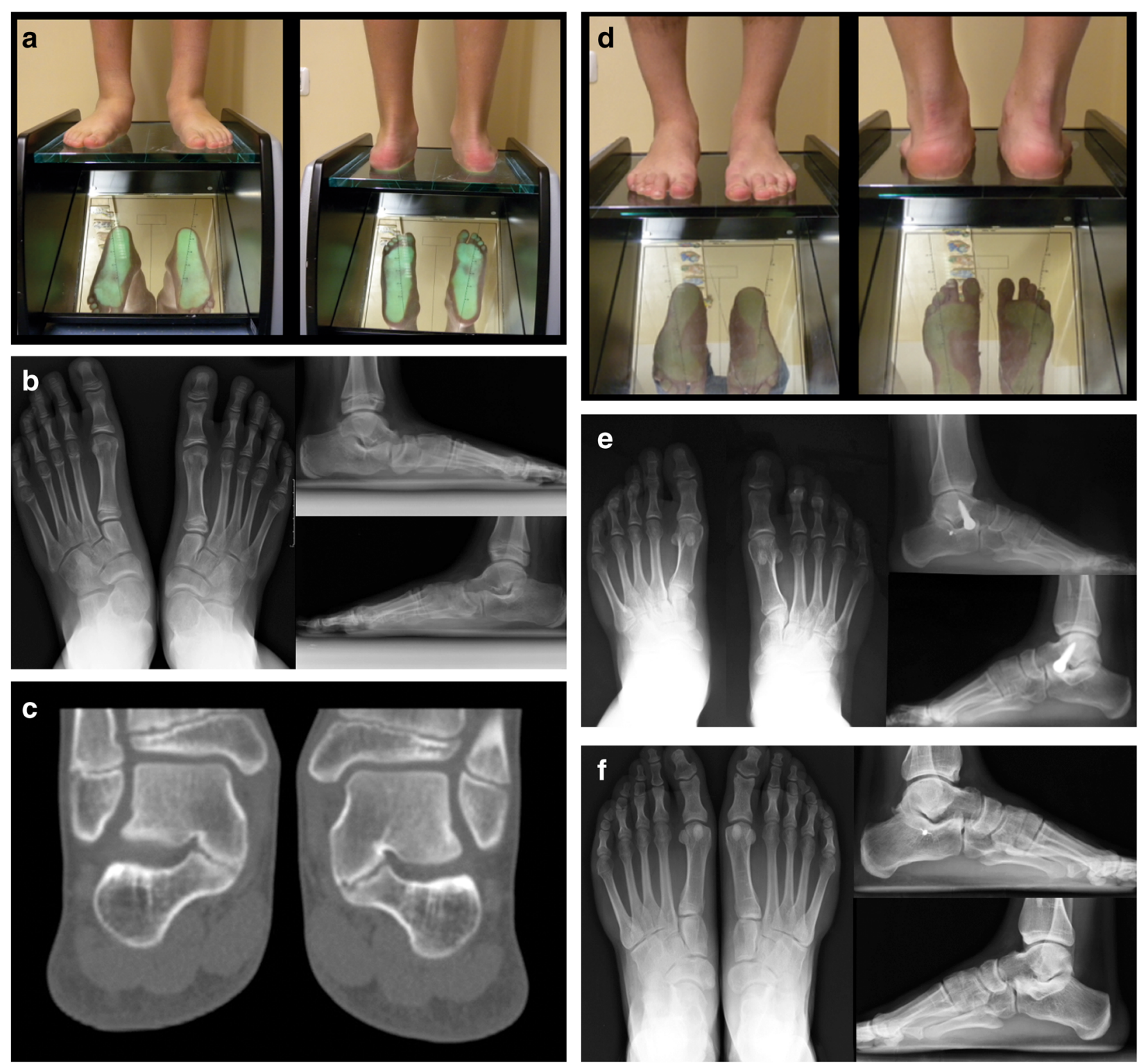

Fig. 2 Clinical and radiographic features of 12 years old boy with RFF and TCC. a Clinical aspect on podoscope. b Antero-posterior and lateral radiographs of the same patient showing the collapse of the longitudinal arch, hindfoot valgus, and forefoot abduction. The "talar beak", evident on the neck of the talus, suggests the presence of TCC. c Coronal CT scan of both feet showing "type I" TCC according to the Rozansky's classification. d Post-operative clinical aspect on podoscope 1 month after surgery. e Radiographic aspect showing the screw arthroeresis with correction of the flatfoot. $\mathbf{f}$ Radiographs 6 years after screw removal, showing that the correction is maintained, and the radiographic parameters are restored

but refuse surgery. We believe that efforts should be done to avoid costly and time consuming nonoperative attempts, if they are destined to fail or to be unsatisfactory for the patient. A possible prognostic factor could be the level of pain at baseline as recently suggested by Birisik [14]; therefore, children with high level of pain could be addressed directly with surgical treatment.

If surgery is considered as definitive management, the surgeon must keep in mind the goals of surgery: to eliminate pain and improve function [13, 64].
Currently, there is no complete agreement concerning the best surgical strategy in children with RFF and TCC. Recommended treatments include bar resection alone or combined with tissue interposition and hindfoot correction $[5,8,19,24,26,29,33,36,39-57,59]$, isolated calcaneal osteotomy [13], subtalar fusion or triple arthrodesis; the latter being recommended for subtalar $\mathrm{OA}$, failure of previous surgeries, or large irresectable coalitions with severe heel valgus $[17,18,39,41]$. The known poor long-term outcomes of triple arthrodesis, 


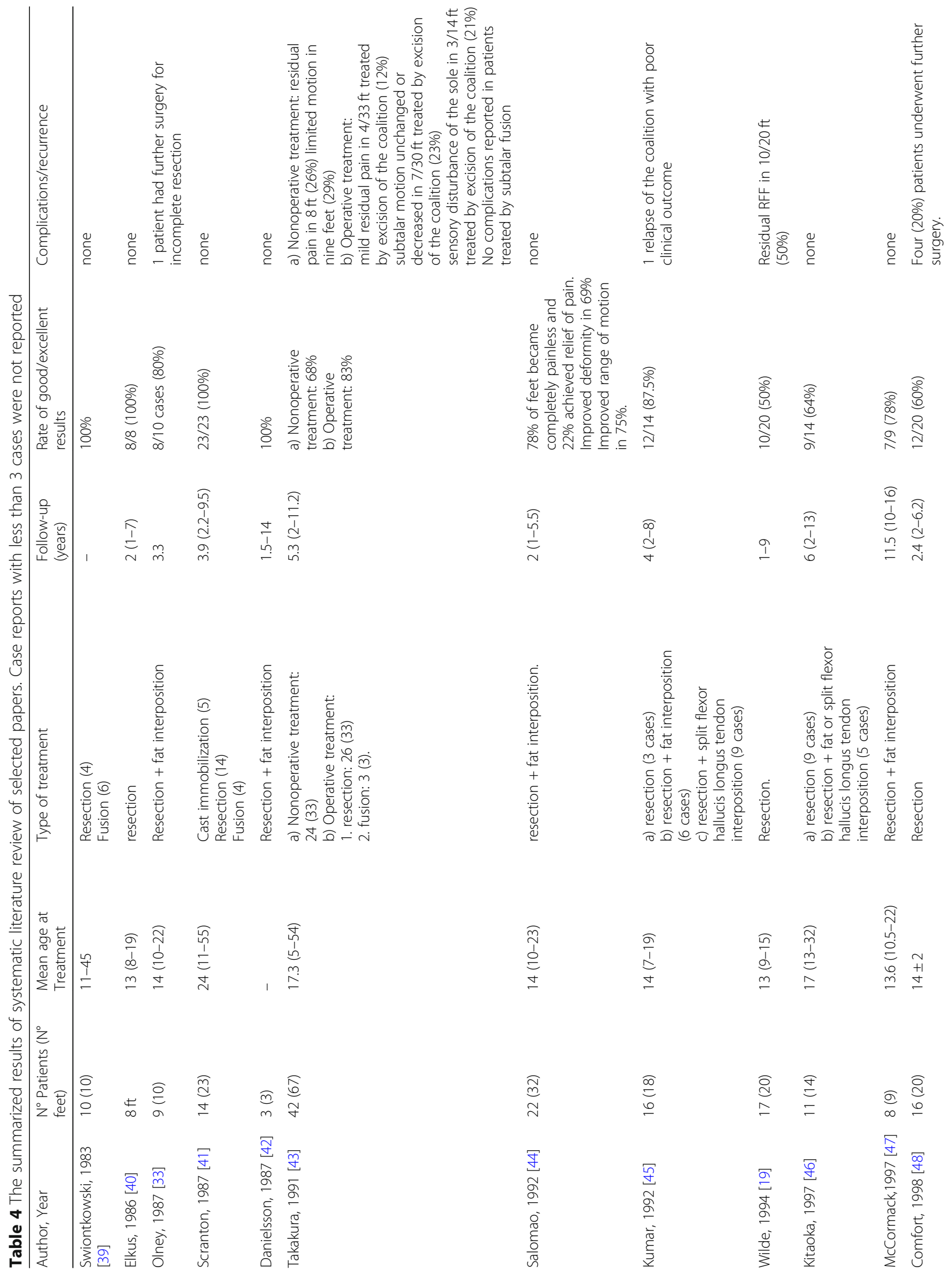




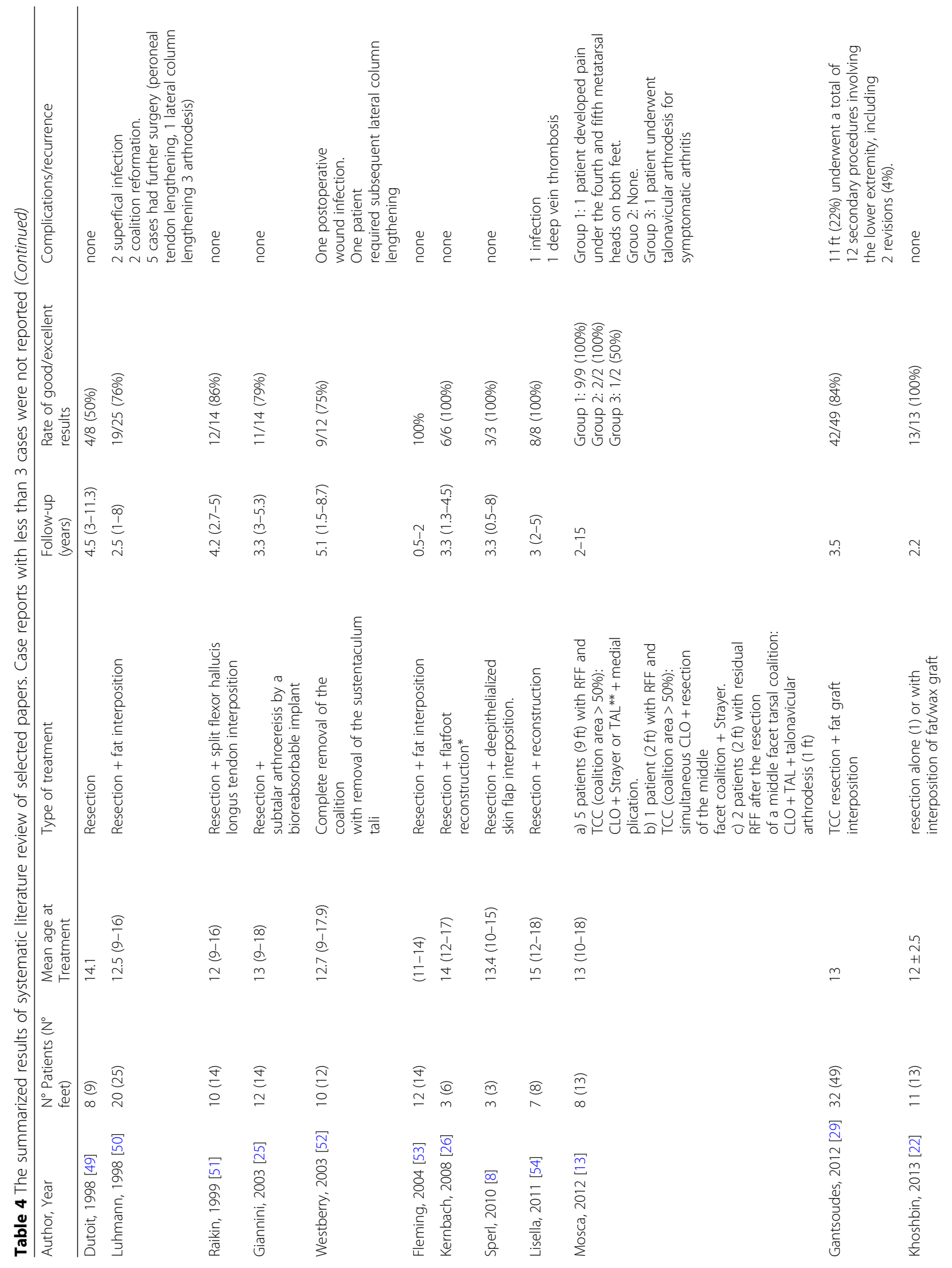




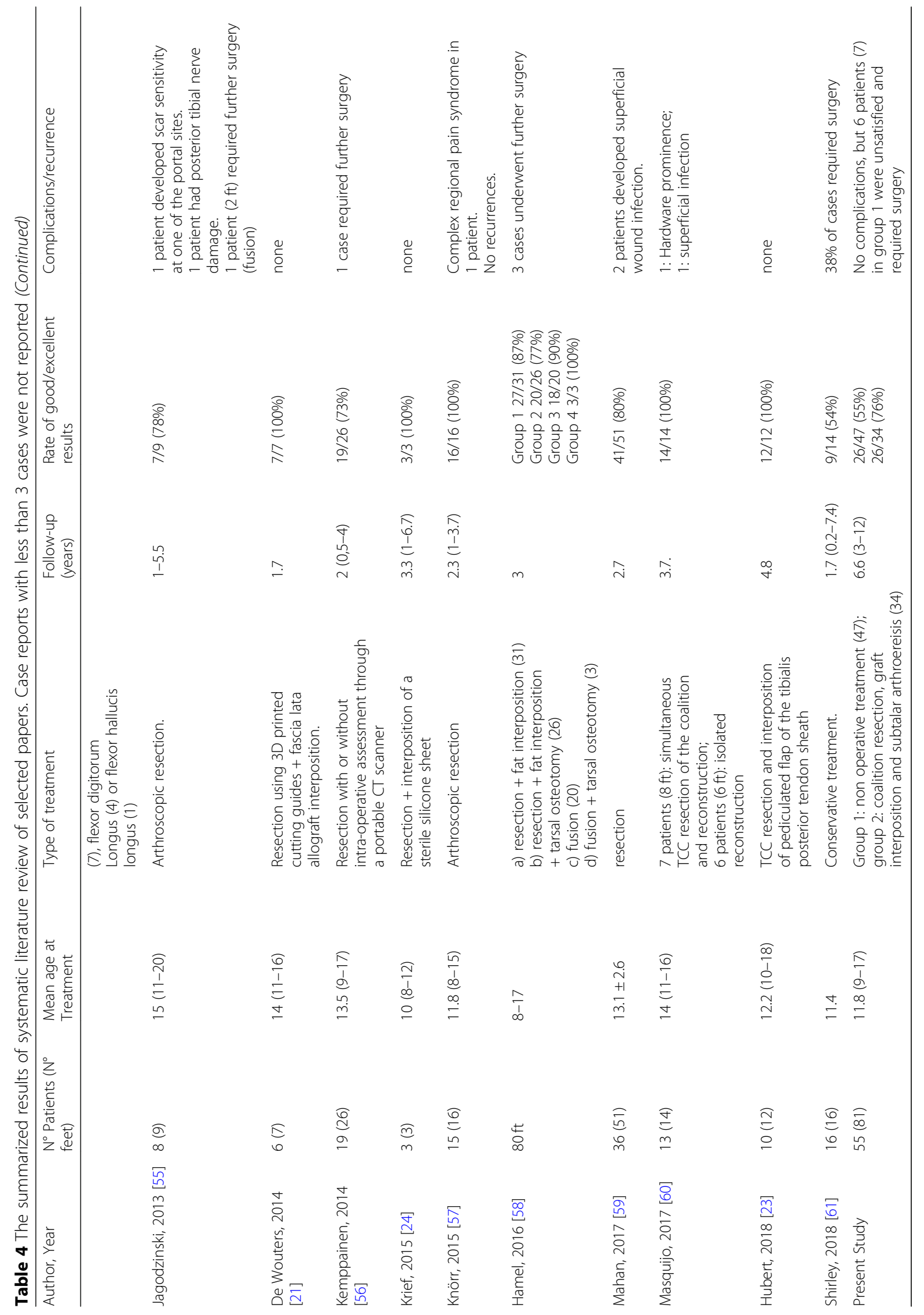


however, make this an undesirable option, particularly for children [16].

Concerning the resection of the coalition, several authors reported favorable results in children with isolated TCC resection.

Wilde et al. reported results from 17 children $(20 \mathrm{ft})$ undergoing TCC resection and fat interposition [19]. He found that heel valgus $>16^{\circ}$, coalition area $>50 \%$, JSN and impingement of the lateral talar process on the calcaneum were predictors of symptoms' recurrence after surgery. Gantsoudes et al. [29] analyzed a cohort of 32 children $(49 \mathrm{ft})$ treated with TCC resection and fat tissue interposition. They reported satisfactory results in $42 \mathrm{ft}$ $(84 \%)$, but $11 \mathrm{ft}$ required secondary procedures, in particular 8 corrective osteotomies to realign the hindfoot. The authors aknowledged that a valgus heel could worsen the outcome but they abitually postponed the hindfoot correction, since the use of a cast for eigth weeks could increase the likelyhood of relapse.

Mosca reported outcomes from a cohort of children who underwent isolated calcaneal osteotomy for RFF with TCC, concluding that heel valgus correction may achieve pain relief, whether or not the coalition is resected [13].

Based on our experience, the heel valgus, whenever present, should be addressed along with the TCC, in order to avoid symptomatic recurrence and need for reoperation.

In our practice, the subtalar arthroereisis is the preferred technique to address the heel valgus in children. Currently, this technique is commonly used to address painful flexible flatfoot in children [65-68]. The main advantages include minimal invasiveness, short surgical time, early return to daily activities, favorable and durable results with low rate of complications. The lateral arthroereisis does not burn any bridges for future treatment modalities, making this procedure suitable for children [68]. Compared to the calcaneal osteotomy [13, 29], the screw arthroereisis limits or does not require a long time of cast immobilization [10, 67, 69, 70]. Moreover, there is initial evidence that lateral arthroereisis may offer a potentially less-invasive alternative to lateral column lengthening [71]. On the other hand, potential disadvantages and complications of the subtalar arthroereisis include loosening, breakage of the implant, pain and discomfort at the surgical incision, peroneal spasm, joint effusion, stress fracture and infection [69, $70,72,73]$. Although there is no evidence about the role of the hardware removal, in our practice we routinely remove the calcaneo-stop screw 2 years after surgery. This procedure maybe reduces the likelihood of breakage or loosening of the screw, residual pain and increase the subtalar motion without significant relapse of the heel valgus deformity.
Some brief reports and short case-series describe the association of TCC resection and hindfoot realignment in children [25, 26, 54, 58, 60].

Giannini et al. investigated 12 children (14ft) undergoing TCC resection and subtalar arthroereisis by bioresorbable screw, reporting improvement of the subtalar motion in $13 / 14$ patients, complete restoration of alignment in $3 \mathrm{ft}$, partial in the remaining 11 $\mathrm{ft}$ and pain improvement in all cases, at a mean follow-up of 3 years. The authors demonstrated that hindfoot alignment, subtalar motion, and age at surgery were predictors of symptoms' recurrence after surgery [25]. These findings were confirmed also in other studies, suggesting that, whenever indicated, this kind of surgery should be undertaken at an early age, before the arthritic changes of the subtalar joint might jeopardize the outcomes [19, 27].

Kernback described excellent results in 3 children with RFF and TCC, undergoing combined TCC resection and calcaneal osteotomy [26].

To the best of our knowledge, we presented the largest series of RFF with TCC in children, comparing nonoperative and operative management. Nonetheless, this study has weaknesses. The retrospective design and lack of randomization introduced potential biases. In particular, the follow-up period was different between the two groups and insufficient for the potential onset of subtalar OA, especially in the operative group. We performed propensity analysis and statistical adjustment to correct or mitigate biases, nonetheless the concern remains. Few postoperative radiographs were available, therefore, no conclusion could be drawn about radiographic correction, recurrence of coalition, and onset of radiographic OA.

The AOFAS-AHS is a clinician-based outcome measure, which lacks sufficient reliability, validity and numeric threshold for a clinically significant difference [74].

To overcome this issue, we administered the FADI at the latest visit, but the lack of a preoperative patientreported measure limits any consideration about the real effectiveness of both treatments from the patient's perspective. The study compared two possible ways to manage RFF and TCC, thus it cannot completely answer to some important questions such as the role of manipulation over just immobilization, the risk-effectiveness and cost-effectiveness of the anesthesia, the effect of the arthroereisis over just resection and the comparison with other surgical procedures, such as osteotomies. The allograft interposition possibly reduces the rate of relapse and increases subtalar motion but increases the costs of the procedure; therefore, additional studies must be conducted to demonstrate the superiority of the allograft over autograft (fat tissue, tendon sheath), silicone or bone wax. 


\section{Conclusion}

Our study describes a one-step procedure combining TCC resection, graft interposition and subtalar arthroereisis. This procedure produced better outcomes in comparison to the nonoperative treatment, increasing subtalar motion and improving foot posture in most cases. Further prospective randomized studies are needed to confirm our findings and to try to identify the best surgical option to treat this condition.

\section{Abbreviations \\ RFF: Rigid flatfoot; FFF: Flexible flatfoot; TCC: Talocalcaneal coalition; CNC: Calcaneonavicular coalition; CT: Computed Tomography; AOFAS- AHS: American Orthopaedic Foot and Ankle Society - Ankle Hindfoot Score; JSN: Joint space narrowing; OA: Osteoarthritis; FADI: Foot and Ankle Disability Index; PS: Propensity Score; IPTW: Inverse probability of treatment weights}

\section{Acknowledgements}

We thank Maria Pia Cumani from the School of Anatomical Drawing of the Rizzoli Orthopedic Institute for the original artwork in Fig. 1, illustrating the surgical technique. We also thank Elettra Pignotti for her support in statistical analysis.

\section{Authors' contributions}

Conception and study design, analysis and data interpretation: GLDG, SS, GT. Data acquisition: PZ, MM, TT. Manuscript drafting and revision: GLDG, SS, EO, SSti, GT. All authors read and approved the final manuscript.

\section{Funding}

The authors received no financial support for the research, authorship, and/ or publication of this article.

\section{Availability of data and materials}

The datasets used and/or analyzed during the current study are available from the corresponding author on reasonable request.

\section{Ethics approval and consent to participate}

Ethics approval was sought and obtained from the Central Emilia Wide Area Ethical Committee of the Emilia-Romagna region (CE-AVEC) (PG nr. 0000315). The study was conducted in accordance with the Helsinki declaration and al patients gave informed consent in writing to participate. Parents provided written consent for the inclusion of the patients in this study, since all the patients were minors (age less than 18) at the time of participation in the study.

\section{Consent for publication}

Not applicable.

\section{Competing interests}

The authors declare that they have no competing interests.

\section{Author details}

${ }^{1}$ Pediatric Orthopedics and Traumatology, IRCCS Istituto Ortopedico Rizzoli, Bologna, Italy. ${ }^{2}$ RAMSES Laboratory, RIT Department, IRCCS Istituto Ortopedico Rizzoli, Bologna, Italy.

Received: 5 November 2019 Accepted: 13 March 2020 Published online: 24 March 2020

\section{References}

1. Lawrence DA, Rolen MF, Haims AH, Zayour Z, Moukaddam HA. Tarsal coalitions: radiographic, CT, and MR imaging findings. HSS J. 2014;10(2): 153-66.

2. Stormont DM, Peterson HA. The relative incidence of tarsal coalition. Clin Orthop Relat Res. 1983;181:28-36

3. Linklater J, Hayter $\mathrm{CL}, \mathrm{Vu}$ D, Tse K. Anatomy of the subtalar joint and imaging of talo-calcaneal coalition. Skelet Radiol. 2009;38(5):437-49.

4. Nalaboff KM, Schweitzer ME. MRI of tarsal coalition: frequency, distribution, and innovative signs. Bull NYU Hosp Jt Dis. 2008;66(1):14-21.
5. Solomon LB, Ruhli FJ, Taylor J, Ferris L, Pope R, Henneberg M. A dissection and computer tomograph study of tarsal coalitions in 100 cadaver feet. J Orthop Res. 2003;21(2):352-8.

6. Murphy JS, Mubarak SJ. Talocalcaneal Coalitions. Foot Ankle Clin. 2015;20(4): $681-91$

7. Carr JB 2nd, Yang S, Lather LA. Pediatric Pes Planus: a state-of-the-art review. Pediatrics. 2016;137(3):e20151230.

8. Sperl M, Saraph V, Zwick EB, Kraus T, Spendel S, Linhart WE. Preliminary report: resection and interposition of a deepithelialized skin flap graft in tarsal coalition in children. J Pediatr Orthop B. 2010;19(2):171-6.

9. Cass AD, Camasta CA. A review of tarsal coalition and pes planovalgus: clinical examination, diagnostic imaging, and surgical planning. J Foot Ankle Surg. 2010;49(3):274-93.

10. Pavone V, Vescio A, Di Silvestri CA, Andreacchio A, Sessa G, Testa G. Outcomes of the calcaneo-stop procedure for the treatment of juvenile flatfoot in young athletes. J Child Orthop. 2018;12(6):582-9.

11. Kerr CM, Zavatsky AB, Theologis T, Stebbins J. Kinematic differences between neutral and flat feet with and without symptoms as measured by the Oxford foot model. Gait Posture. 2019;67:213-8.

12. Bernasconi A, Lintz F, Sadile F. The role of arthroereisis of the subtalar joint for flatfoot in children and adults. EFORT Open Rev. 2017:2(11):438-46.

13. Mosca VS, Bevan WP. Talocalcaneal tarsal coalitions and the calcaneal lengthening osteotomy: the role of deformity correction. J Bone Joint Surg Am. 2012;94(17):1584-94

14. Birisik F, Demirel M, Bilgili F, Salduz A, Yeldan I, Ismet Kilicoglu O. The natural course of pain in patients with symptomatic tarsal coalitions: a retrospective clinical study. Foot Ankle Surg. 2020;26(2):228-32. https://doi.org/10.1016/jfas.2019.03.002.

15. Docquier $\mathrm{PL}$, Maldaque $\mathrm{P}$, Bouchard M. Tarsal coalition in paediatric patients. Orthop Traumatol Surg Res. 2019;105(1S):S123-S31.

16. Mosca VS. Subtalar coalition in pediatrics. Foot Ankle Clin. 2015;20(2):265-81.

17. Peterson HA. Dowel bone graft technique for triple arthrodesis in talocalcaneal coalition--report of a case with 12-year follow-up. Foot Ankle. 1989:9(4):201-3.

18. Cowell HR. Talocalcaneal coalition and new causes of peroneal spastic flatfoot. Clin Orthop Relat Res. 1972;85:16-22.

19. Wilde PH, Torode IP, Dickens DR, Cole WG. Resection for symptomatic talocalcaneal coalition. J Bone Joint Surg Br. 1994;76(5):797-801.

20. McCormack AP, Niki H, Kiser P, Tencer AF, Sangeorzan BJ. Two reconstructive techniques for flatfoot deformity comparing contact characteristics of the hindfoot joints. Foot Ankle Int. 1998 Jul;19(7):452-61.

21. de Wouters S, Tran Duy K, Docquier PL. Patient-specific instruments for surgical resection of painful tarsal coalition in adolescents. Orthop Traumatol Surg Res. 2014 Jun;100(4):423-7.

22. Khoshbin A, Law PW, Caspi L, Wright JG. Long-term functional outcomes of resected tarsal coalitions. Foot Ankle Int. 2013;34(10):1370-5.

23. Hubert J, Hawellek T, Beil FT, Saul D, Kling JH, Viebahn C, et al. Resection of medial Talocalcaneal coalition with interposition of a Pediculated flap of Tibialis posterior tendon sheath. Foot Ankle Int. 2018 Aug;39(8):935-41.

24. Krief E, Ferraz L, Appy-Fedida B, Deroussen F, Plancq MC, Collet LM, et al. Tarsal coalitions: preliminary results after operative excision and silicone sheet interposition in children. J Foot Ankle Surg. 2016;55(6):1264-70.

25. Giannini S, Ceccarelli F, Vannini F, Baldi E. Operative treatment of flatfoot with talocalcaneal coalition. Clin Orthop Relat Res. 2003;411:178-87.

26. Kernbach KJ, Blitz NM, Rush SM. Bilateral single-stage middle facet talocalcaneal coalition resection combined with flatfoot reconstruction: a report of 3 cases and review of the literature. Investigations involving middle facet coalitions--part 1. J Foot Ankle Surg. 2008;47(3):180-90.

27. Philbin TM, Homan B, Hill K, Berlet G. Results of resection for middle facet tarsal coalitions in adults. Foot Ankle Spec. 2008;1(6):344-9.

28. Quinn EA, Peterson KS, Hyer CF. Calcaneonavicular coalition resection with Pes Planovalgus reconstruction. J Foot Ankle Surg. 2016;55(3):578-82.

29. Gantsoudes GD, Roocroft JH, Mubarak SJ. Treatment of talocalcaneal coalitions. J Pediatr Orthop. 2012;32(3):301-7.

30. Chang $\mathrm{CH}$, Chen YC, Yang WT, Ho PC, Hwang AW, Chen $\mathrm{CH}$, et al. Flatfoot diagnosis by a unique bimodal distribution of footprint index in children. PLoS One. 2014;9(12):e115808.

31. Banwell HA, Paris ME, Mackintosh S, Williams CM. Paediatric flexible flat foot: how are we measuring it and are we getting it right? A systematic review. J Foot Ankle Res. 2018;11:21.

32. Leigheb M, Janicka P, Andorno S, Marcuzzi A, Magnani C, Grassi F. Italian translation, cultural adaptation and validation of the "American Orthopaedic Foot and Ankle Society's (AOFAS) ankle-hindfoot scale". Acta Biomed. 2016;87(1):38-45. 
33. Olney BW, Asher MA. Excision of symptomatic coalition of the middle facet of the talocalcaneal joint. J Bone Joint Surg Am. 1987;69(4):539-44.

34. Rozansky A, Varley E, Moor M, Wenger DR, Mubarak SJ. A radiologic classification of talocalcaneal coalitions based on 3D reconstruction. J Child Orthop. 2010;4(2):129-35.

35. Cohen MM, Vela ND, Levine JE, Barnoy EA. Validating a new computed tomography atlas for grading ankle osteoarthritis. J Foot Ankle Surg. 2015;54(2):207-13.

36. Docquier PL, Paul L, Mousny M, Cornu O, Delloye C. The use of allografts in paediatric orthopaedic surgery. Acta Orthop Belg. 2007;73(5):551-7.

37. Sartorio F, Vercelli S, Bravini E, Bargeri S, Moroso M, Plebani G, et al. Foot and ankle ability measure: cross-cultural translation and validation of the Italian version of the ADL module (FAAM-I/ADL). Med Lav. 2014;105(5):357-65.

38. Pirracchio R, Resche-Rigon $\mathrm{M}$, Chevret $\mathrm{S}$. Evaluation of the propensity score methods for estimating marginal odds ratios in case of small sample size. BMC Med Res Methodol. 2012:12:70.

39. Swiontkowski MF, Scranton PE, Hansen S. Tarsal coalitions: long-term results of surgical treatment. J Pediatr Orthop. 1983;3(3):287-92.

40. Elkus RA. Tarsal coalition in the young athlete. Am J Sports Med. 1986;14(6): 477-80.

41. Scranton PE Jr. Treatment of symptomatic talocalcaneal coalition. J Bone Joint Surg Am. 1987;69(4):533-9.

42. Danielsson LG. Talo-calcaneal coalition treated with resection. J Pediatr Orthop. 1987:7(5):513-7.

43. Takakura Y, Sugimoto K, Tanaka Y, Tamai S. Symptomatic talocalcaneal coalition. Its clinical significance and treatment. Clin Orthop Relat Res. 1991; 269:249-56.

44. Salomao O, Napoli MM, de Carvalho Junior AE, Fernandes TD, Marques J, Hernandez AJ. Talocalcaneal coalition: diagnosis and surgical management. Foot Ankle. 1992;13(5):251-6.

45. Kumar SJ, Guille JT, Lee MS, Couto JC. Osseous and non-osseous coalition of the middle facet of the talocalcaneal joint. J Bone Joint Surg Am. 1992;74(4): 529-35.

46. Kitaoka HB, Wikenheiser MA, Shaughnessy WJ, An KN. Gait abnormalities following resection of talocalcaneal coalition. J Bone Joint Surg Am. 1997; 79(3):369-74.

47. McCormack TJ, Olney B, Asher M. Talocalcaneal coalition resection: a 10-year follow-up. J Pediatr Orthop. 1997;17(1):13-5.

48. Comfort TK, Johnson LO. Resection for symptomatic talocalcaneal coalition. J Pediatr Orthop. 1998;18(3):283-8.

49. Dutoit M. Talocalcaneal bar resection. J Foot Ankle Surg. 1998:37(3):199-203.

50. Luhmann SJ, Schoenecker PL. Symptomatic talocalcaneal coalition resection: indications and results. J Pediatr Orthop. 1998;18(6):748-54

51. Raikin S, Cooperman DR, Thompson GH. Interposition of the split flexor hallucis longus tendon after resection of a coalition of the middle facet of the talocalcaneal joint. J Bone Joint Surg Am. 1999;81(1):11-9.

52. Westberry DE, Davids JR, Oros W. Surgical management of symptomatic talocalcaneal coalitions by resection of the sustentaculum tali. J Pediatr Orthop. 2003;23(4):493-7.

53. Fleming P, Rice JJ, Kelly I, Stephens M. Resection of talocalcaneal coalition-the effect on subtalar joint movements. Foot Ankle Surg. 2004;10(1):13-6.

54. Lisella JM, Bellapianta JM, Manoli A 2nd. Tarsal coalition resection with pes planovalgus hindfoot reconstruction. J Surg Orthop Adv. 2011 Summer; 20(2):102-5.

55. Jagodzinski NA, Hughes A, Davis NP, Butler M, Winson IG, Parsons SW. Arthroscopic resection of talocalcaneal coalitions--a bicentre case series of a new technique. Foot Ankle Surg. 2013;19(2):125-30.

56. Kemppainen J, Pennock AT, Roocroft JH, Bastrom TP, Mubarak SJ. The use of a portable CT scanner for the intraoperative assessment of talocalcaneal coalition resections. J Pediatr Orthop. 2014;34(5):559-64.

57. Knorr J, Soldado F, Menendez ME, Domenech P, Sanchez M, Sales de Gauzy J. Arthroscopic Talocalcaneal coalition resection in children. Arthroscopy. 2015;31(12):2417-23

58. Hamel J, Nell M, Rist C. Surgical treatment of talocalcaneal coalition : experience with 80 cases of pediatric or adolescent patients. Orthopade. 2016;45(12):1058-65

59. Mahan ST, Prete VI, Spencer SA, Kasser JR, Bixby SD. Subtalar coalitions: does the morphology of the subtalar joint involvement influence outcomes after coalition excision? J Foot Ankle Surg. 2017;56(4):797-801.

60. Javier Masquijo J, Vazquez I, Allende V, Lanfranchi L, Torres-Gomez A, Dobbs MB. Surgical reconstruction for Talocalcaneal coalitions with severe Hindfoot Valgus deformity. J Pediatr Orthop. 2017;37(4):293-7.
61. Shirley E, Gheorghe R, Neal KM. Results of nonoperative treatment for symptomatic tarsal coalitions. Cureus. 2018;10(7):e2944.

62. Rouvreau P, Pouliquen JC, Langlais J, Glorion C, de Cerqueira Daltro G. Synostosis and tarsal coalitions in children. A study of 68 cases in 47 patients. Rev Chir Orthop Reparatrice Appar Mot. 1994;80(3):252-60.

63. Saxena A, Erickson S. Tarsal coalitions. Activity levels with and without surgery. J Am Podiatr Med Assoc. 2003;93(4):259-63.

64. Gougoulias N, O'Flaherty M, Sakellariou A. Taking out the tarsal coalition was easy: but now the foot is even flatter. What now? Foot Ankle Clin. 2014;19(3):555-68.

65. Jay RM, Din N. Correcting pediatric flatfoot with subtalar arthroereisis and gastrocnemius recession: a retrospective study. Foot Ankle Spec. 2013;6(2): $101-7$.

66. Caravaggi P, Lullini G, Berti L, Giannini S, Leardini A. Functional evaluation of bilateral subtalar arthroereisis for the correction of flexible flatfoot in children: 1-year follow-up. Gait Posture. 2018;64:152-8.

67. Pavone V, Costarella L, Testa G, Conte G, Riccioli M, Sessa G. Calcaneo-stop procedure in the treatment of the juvenile symptomatic flatfoot. J Foot Ankle Surg. 2013;52(4):444-7.

68. Ortiz CA, Wagner E, Wagner P. Arthroereisis: what have we learned? Foot Ankle Clin. 2018;23(3):415-34

69. Pavone V, Vescio A, Canavese F, Costa D, Sessa G, Testa G. Effects of body weight on the clinical and radiological outcomes of children with flexible flatfeet managed with the 'calcaneo-stop' procedure. J Pediatr Orthop B. 2019;28(3):228-34.

70. De Pellegrin M, Moharamzadeh D, Strobl WM, Biedermann R, Tschauner C, Wirth T. Subtalar extra-articular screw arthroereisis (SESA) for the treatment of flexible flatfoot in children. J Child Orthop. 2014;8(6):479-87.

71. Chong DY, Macwilliams BA, Hennessey TA, Teske N, Stevens PM. Prospective comparison of subtalar arthroereisis with lateral column lengthening for painful flatfeet. J Pediatr Orthop B. 2015;24(4):345-53.

72. Hsieh CH, Lee CC, Tseng TH, Wu KW, Chang JF, Wang TM. Body weight effects on extra-osseous Subtalar Arthroereisis. J Clin Med. 2019;8(9). https:// doi.org/10.3390/jcm8091273

73. Metcalfe SA, Bowling FL, Reeves ND. Subtalar joint arthroereisis in the management of pediatric flexible flatfoot: a critical review of the literature. Foot Ankle Int. 2011:32(12):1127-39.

74. Kitaoka HB, Meeker JE, Phisitkul P, Adams SB Jr, Kaplan JR, Wagner E. AOFAS position statement regarding patient-reported outcome measures. Foot Ankle Int. 2018;39(12):1389-93.

\section{Publisher's Note}

Springer Nature remains neutral with regard to jurisdictional claims in published maps and institutional affiliations.
Ready to submit your research? Choose BMC and benefit from:

- fast, convenient online submission

- thorough peer review by experienced researchers in your field

- rapid publication on acceptance

- support for research data, including large and complex data types

- gold Open Access which fosters wider collaboration and increased citations

- maximum visibility for your research: over $100 \mathrm{M}$ website views per year

At BMC, research is always in progress.

Learn more biomedcentral.com/submissions 